\title{
An overview of the Energy Modeling Forum 33rd study: assessing large-scale global bioenergy deployment for managing climate change
}

\author{
Steven K Rose ${ }^{1}$ (D) Nico Bauer ${ }^{2}$ - Alexander Popp ${ }^{2} \cdot$ John Weyant $^{3}$ • \\ Shinichiro Fujimori ${ }^{4,5,6}$ - Petr Havlik ${ }^{6}$ - Marshall Wise ${ }^{7}$. Detlef P van Vuuren ${ }^{8,9}$
}

Received: 28 October 2020 / Accepted: 5 November 2020/Published online: 05 December 2020

(C) Springer Nature B.V. 2020

\begin{abstract}
Previous studies have projected a significant role for bioenergy in decarbonizing the global economy and helping realize international climate goals such as limiting global average warming to $2{ }^{\circ} \mathrm{C}$ or $1.5{ }^{\circ} \mathrm{C}$. However, with substantial variability in bioenergy results and significant concerns about potential environmental and social implications, greater transparency and dedicated assessment of the underlying modeling and results and more detailed understanding of the potential role of bioenergy are needed. Stanford University's Energy Modeling Forum (EMF) initiated a 33rd study (EMF-33) to explore the viability of largescale bioenergy as part of a comprehensive climate management strategy. This special issue presents the papers of the EMF-33 study - a multi-year inter-model comparison project designed to understand and assess global, long-run biomass supply and bioenergy
\end{abstract}

This article is part of the Special Issue on "Assessing Large-scale Global Bioenergy Deployment for Managing Climate Change (EMF-33)"

Steven K Rose

srose@epri.com

1 Energy Systems and Climate Analysis Research Group, Electric Power Research Institute (EPRI), Washington, DC, USA

2 Potsdam Institute for Climate Impact Research, Leibniz Association, Potsdam, Germany

3 Stanford University, Stanford, CA, USA

4 Department of Environmental Engineering, Kyoto University, Kyoto, Japan

5 Center for Social and Environmental Systems Research, National Institute for Environmental Studies, Tsukuba, Japan

6 International Institute for Applied System Analysis, Laxenburg, Austria

7 Joint Global Change Research Institute, Pacific Northwest National Laboratory \& Univ. of Maryland, College Park, MD, USA

8 PBL Netherlands Environmental Assessment Agency, The Hague, Netherlands

9 Copernicus Institute of Sustainable Development, Utrecht University, Utrecht, Netherlands 
deployment potentials and related uncertainties. Using a novel scenario design with independent biomass supply and bioenergy demand protocols, EMF-33 separately elucidates and explores the modeling of biomass feedstock supplies and bioenergy technologies and their deployment - revealing, comparing, and assessing the modeling that is suggesting that bioenergy could be a key climate containment strategy. This introduction provides an overview of the EMF-33 study design and the overview, thematic, and individual modeling team papers and types of insights that make up this special issue. By providing enhanced transparency and new detailed insights, we hope to inform policy dialogue about the potential role of bioenergy and facilitate new research.

Keywords Biomass $\cdot$ Bioenergy $\cdot$ Decarbonization $\cdot$ Climate change $\cdot$ Emissions scenarios

\section{Introduction}

Bioenergy has been found to be a potentially valuable, and maybe essential, strategy for longrun climate management, especially for achieving very low climate change objectives (e.g., Rogelj et al. 2018; Creutzig et al. 2015; Gasser et al. 2015; Clarke et al. 2014; Rose et al. 2014). Past modeling results suggest that bioenergy is a flexible fuel that could contribute to energy needs and long-run decarbonization in many parts of the economy, with bioenergy combined with carbon dioxide capture and storage (BECCS) a particularly enticing strategy given its potential to effectively remove carbon from the atmosphere. However, the scale of advanced bioenergy technology deployments implied and potential side effects, including land-use competition, biodiversity loss, food security impacts, and effects on other environmental services (e.g., Hof et al. 2018; Hasegawa et al. 2020; Smith et al. 2014; Creutzig et al. 2013; Humpenöder et al. 2018) have led to concern and debate about bioenergy. Other issues are also being discussed, including questions about net carbon benefits, carbon accounting, and global temperature overshoots and the role of bioenergy as a technology that removes carbon dioxide $\left(\mathrm{CO}_{2}\right)$ from the atmosphere.

To date, however, there has been significant variation in projections of potential bioenergy deployment, and uncertainty about the social and environmental implications and technological challenges associated with large-scale deployment (e.g., Popp et al. 2014; Rose et al. 2014; Rogelj et al. 2018; Daioglou et al. 2020c). As a result, the attributes and implications of and potential conditions for large-scale global bioenergy deployment are not well characterized (Shukla et al. 2019). Thus, the literature provides mixed messages as to what is possible or harmful and for what purposes bioenergy should be used. This presents a challenge to national and international policy, and research and development, attempting to advance domestic greenhouse gas reduction initiatives for individual economic sectors, terrestrial ecosystems, and entire economies, as well as international climate objectives such as the UNFCCC Paris Agreement's goal of limiting global mean warming to below $2{ }^{\circ} \mathrm{C}$, and potentially below $1.5^{\circ} \mathrm{C}$.

In this context, we initiated the 33rd study of Stanford University's Energy Modeling Forum (EMF-33) to explore the viability of large-scale bioenergy as part of a comprehensive climate management strategy. The EMF-33 study is a multi-year model inter-comparison project designed to understand and assess global and regional, long-run, biomass supply and bioenergy demand potentials and related uncertainties. The study brings together integrated assessment modeling teams to elucidate, compare, and assess the models suggesting that bioenergy could be a key climate change containment strategy. Using independent scenario 
protocols, EMF-33 separately explores the modeling of (i) biomass feedstock supplies and (ii) bioenergy technologies and their deployment in century-long global decarbonization.

\section{EMF-33 study design}

\subsection{Study objectives and modeling teams}

EMF-33's objectives are to understand and assess global, long-run, bioenergy potentials and uncertainties and, by doing so, inform questions regarding the long-run viability of large-scale global bioenergy. The participating models and scenario designs are chosen to increase transparency and understanding of bioenergy's long-run global potential for managing climate.

The study brings together twelve integrated assessment modeling teams (Table 1). The participating models represent a prominent and significant fraction of the modeling community that evaluates potential long-run climate management strategies. From the outset, the models differ structurally in their representation of biomass feedstocks and bioenergy technologies (Table 1). In addition, some teams integrate specialized detailed models that separately represent global land use and biomass feedstock supply production from global energy systems and the economy. These models have hyphenated names in Table 1, with the energy/economy modeling component listed first followed by the land use modeling component. The biomass supply modeling assessment exercise described below uses only the land use modeling component from these models.

\subsection{Scenario design}

Under EMF-33, we design separate biomass supply and demand scenario experiments for diagnostics and specific insights regarding the feasibility (quantities, timing, implications) of large-scale biomass supply, bioenergy technology deployment, and energy sector integration. Specifically, separate supply and demand scenario protocols explore the modeling of biomass supplies and bioenergy technologies and deployments.

Tables 2 and 3 summarize the biomass supply and bioenergy demand scenario experimental designs. Our focus is on potential modern biomass supply and use, defined as cellulosic biomass feedstocks for energy use (sometimes called "second-generation" biomass). This includes energy crops, logs, and residue feedstocks from agriculture, forestry, or municipal waste, but not traditional biomass use or food crops, such as corn, sugarcane, and soybeans (sometimes called "first-generation" biomass), that can be used for some forms of bioenergy.

The biomass supply scenarios (Table 2) allow for evaluation of the implications of increasing global biomass supply under different conditions regarding land-based mitigation incentives and land protection. The scenario specification isolates and reveals biomass supply modeling behavior and characteristics (costs, emissions, land use, market effects) and elucidates novel insights into the nature of "pure" biomass production and supply within the models. Ten modeling teams participate in the biomass supply experiments, with all teams running the biomass quantity scenarios (Table 2 top) — scenarios driven by an exogenously specified global modern biomass primary energy supply requirement. Some modeling teams also run the biomass price scenarios (Table 2 bottom) - scenarios driven by an exogenously specified global modern biomass price. Models run each quantity scenario as a global demand for additional modern biomass that increases from zero today rising linearly to prescribed 2100 


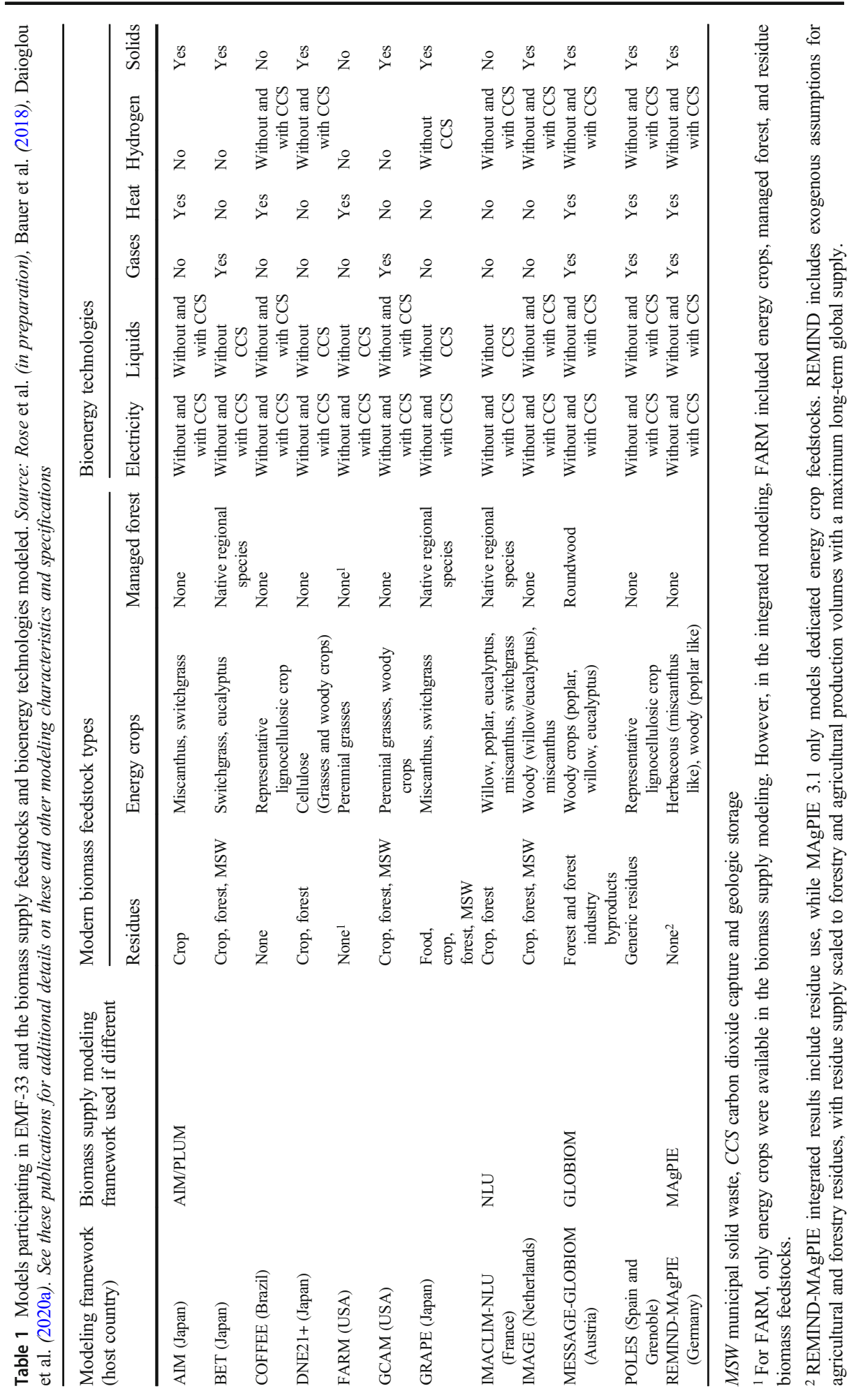


Table 2 Biomass supply assessment scenarios

\begin{tabular}{|c|c|c|c|}
\hline $\begin{array}{l}\text { Scenario } \\
\text { type }\end{array}$ & $\begin{array}{l}\text { Global modern biomass primary energy } \\
\text { supply in } 2100 \text { (above baseline, } \\
\text { increasing } \\
\text { linearly from } 2010, \mathrm{EJ} / \text { year) OR farmgate } \\
\text { price (US } \$ 2005 / \mathrm{GJ} \text { ) }\end{array}$ & $\begin{array}{l}\text { GHG price for land mitigation options } \\
\text { (US } \$ 2005 / \mathrm{tCO}_{2} \text { eq) }\end{array}$ & $\begin{array}{l}\text { Land } \\
\text { protection }\end{array}$ \\
\hline \multirow{4}{*}{$\begin{array}{l}\text { Biomass } \\
\text { quantity }\end{array}$} & $100,200,300$, and $400 \mathrm{EJ}$ & $\$ 0$ & None \\
\hline & $100,200,300$, and $400 \mathrm{EJ}$ & $\$ 20($ in 2020$)+3 \% /$ year & None \\
\hline & $300 \mathrm{EJ}$ & $\$ 0$ & Model default \\
\hline & $300 \mathrm{EJ}$ & $\$ 20($ in 2020$)+3 \% /$ year & Model default \\
\hline \multirow{2}{*}{$\begin{array}{l}\text { Biomass } \\
\text { price }\end{array}$} & $\$ 3, \$ 5, \$ 9$, and $\$ 15$ & $\$ 0$ & None \\
\hline & $\$ 3, \$ 5, \$ 9$, and $\$ 15$ & $\$ 20($ in 2020$)+3 \% /$ year & None \\
\hline
\end{tabular}

levels. Imposing a global biomass supply requirement reveals each model's least-cost biomass production allocation across regions and feedstocks. Furthermore, by increasing the biomass quantity requirements, we identify changes in the least-cost distribution of supply as the quantity supplied increases and the environmental and social implications.

Models run each biomass price scenario as a global price applied to all regions and all time periods. Imposing a biomass price allows us to tease out implicit biomass supply curves from each model and learn about the implied marginal cost of providing biomass globally and regionally.

To properly elucidate each model's implied modern biomass supply and ensure comparable scenario results, modeling teams implement additional scenario specification requirements: standardizing the incremental increase in biomass supply, shutting off elements of bioenergy demand that influence land use and land emissions results, and removing exogenous land protection or set-aside constraints that preclude land access to economically accessible lands. Regarding the latter, only lands already protected from commercial activity or for environmental purposes were off-limits. Finally, modern biomass was defined as cellulosic biomass feedstocks for energy use native to each model. Food crops that can be used for bioenergy and traditional biomass use are not counted against the modern biomass supply requirement. See the EMF-33 biomass supply assessment paper, Rose et al. (in preparation), for additional details regarding biomass supply modeling specifications and the scenario implementation.

The bioenergy demand scenario design (Table 3) allows for evaluation of the potential role of bioenergy with increasingly constrained global emissions futures under different conditions for future bioenergy technology availability and feedstock supply. Integrated modeling frameworks that include the biomass feedstock supply representations and capture interactions with the full energy system and economy run the demand scenarios. The integrated frameworks allow us to explore potential market outcomes for deploying bioenergy technologies and using biomass. Specifically, we evaluate bioenergy futures for three successively smaller energy and industry $\mathrm{CO}_{2}$ emissions budgets through 2100, where the two smallest (1000 and $\left.400 \mathrm{GtCO}_{2}\right)$ are consistent with limiting global average warming to $2{ }^{\circ} \mathrm{C}$ and $1.5^{\circ} \mathrm{C}$ respectively. In each case, we also evaluate the sensitivity of results to the availability and cost of advanced bioenergy technologies and to the availability of biomass feedstocks. For all the budget scenarios, we price non- $\mathrm{CO}_{2}$ and land $\mathrm{CO}_{2}$ emissions according to the $\mathrm{CO}_{2}$ price derived from the energy and industry budget constraints. We also run separate $\mathrm{CO}_{2}$ price (tax) scenarios to 


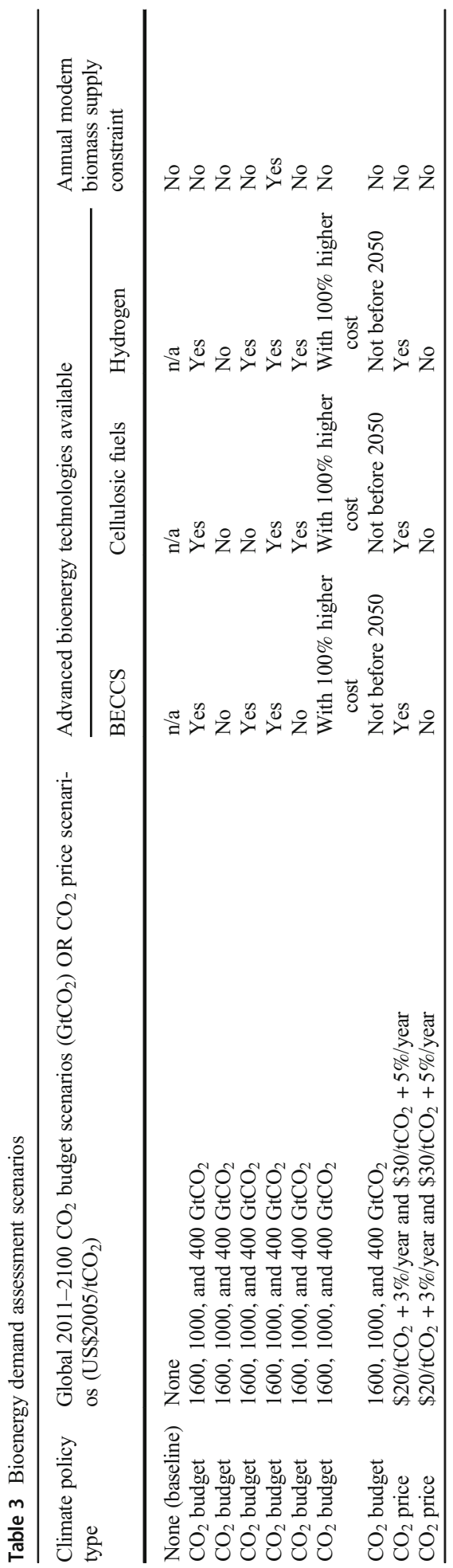


evaluate bioenergy deployment responses to a standardized price. See the EMF-33 bioenergy demand assessment paper, Bauer et al. (2018), for additional details regarding bioenergy demand modeling and the scenario implementation.

Together, the biomass supply and demand experiments yield diverse, but complementary, perspectives on individual biomass feedstocks and regional supplies, bioenergy technology types and deployments, differences and uncertainties between models, and characterizations of potential consequences that help prioritize future research and inform public debate and policy. Note that not all models run all scenarios or produce all reporting variables. Thus, models are represented in the model comparison papers as appropriate given the scenarios and variables relevant to each topic.

\section{EMF-33 special issue papers}

The EMF-33 special issue consists of three types of papers: overview, thematic, and individual modeling team papers. We use cross-model analyses based on inter-model comparisons and the common scenarios described above for the overview and thematic papers. There are two overviews: one assessing biomass supply modeling and the other evaluating bioenergy demand and deployment projections. There are seven thematic papers exploring a range of specific topics, with some topics providing perspectives on additional biomass supply issues (residue feedstock supplies and food security), others providing additional perspectives on bioenergy use (bioenergy technologies, bioenergy in transportation, bioenergy with carbon capture and storage, and bioenergy trade), and still others offering location specific perspective on both supply and demand (bioenergy potential in Brazil). Finally, there are four individual modeling team papers providing focused investigations on additional bioenergy research and policy questions.

\subsection{Overview papers}

Global biomass supply (Rose et al., in preparation) ${ }^{1}$ Using the EMF-33 biomass supply scenario experiments, Rose et al. elucidate, compare, and assess the biomass supply modeling within the models. The paper isolates and reveals biomass supply modeling behavior and characteristics, including the least-cost global distributions of biomass feedstock supplies, and the potential societal externalities of providing biomass (related to land use change, emissions, and food prices). The paper also evaluates the biomass supply effects of managing these externalities, estimates global and regional biomass supply curves, and derives model specific biomass supply narratives. The authors find biomass supply to be defined by its production costs, as well as the environmental and social implications of supplying biomass for energy. They find significant differences between models in the estimated regional and feedstock composition of global biomass supply and its environmental and social implications. The differences in results are due to differences in the feedstocks modeled, allowed land conversions, and other factors that together define the opportunity cost of producing modern biomass, as well as the emissions, land use, land management, and agricultural market implications. They find that

\footnotetext{
${ }^{1}$ In preparation papers are not listed in the references. See the title and authors at the end of each respective paragraph.
} 
managing the land use and emissions externalities of supplying modern biomass affects the least-cost feedstock supply mix as well as the societal cost for food and feed crops and biomass. The authors then use the biomass supply model-specific insights to interpret integrated modeling biomass use market results, finding that bioenergy deployment in integrated modeling takes into account emissions and land use externalities of supplying biomass. The authors conclude that environmental and societal trade-offs may be inevitable; and, even with biomass supply externalities accounted for and internalized, large-scale use of biomass in managing the climate, and trade-offs, could be cost-effective for society. Overall, the paper finds little consensus across models on where biomass could be costeffectively produced and the implications of doing so, which highlights the need for more detailed assessment of opportunities and experience with large-scale projects (Rose $S K$, Popp A, Fujimori S, Havlik P, Weyant J, Wise M, van Vuuren D, Brunelle T, Cui Y, Daioglou V, Frank S, Hasegawa T, Humpenöder F, Kato E, Sands RD, Sano F, Tsutsui J, Doelman J, Muratori M, Prudhomme R, Wada K, Yamamoto H. Global biomass supply modeling for long-run management of the climate system).

Global bioenergy demand and deployment (Bauer et al. 2018) Using the EMF-33 bioenergy demand scenario experiments, Bauer et al. evaluate future bioenergy use across models under increasingly more ambitious climate policies, considering uncertainty about the availability of bioenergy technologies and biomass supply. For all models, bioenergy use increases by 2050 if Paris Agreement compatible climate targets are pursued in a cost-effective manner, with bioenergy substituting for fossil fuels and removing carbon from the atmosphere. Differences in biomass feedstock supply costs and constraints due to land use modeling, sustainable restrictions, and $\mathrm{CO}_{2}$ pricing are key factors behind differences in projected global bioenergy use. Furthermore, models that allow for the conversion of biomass feedstocks into liquid fuels for transportation find this biomass conversion route preferred to electricity generation. The greater challenge of decarbonizing non-electric energy services drives this result despite the higher $\mathrm{CO}_{2}$ removal rate in bioenergy electricity production. Moreover, results excluding BECCS reaffirm previous findings that bioenergy use does not decline in the absence of BECCS availability because higher $\mathrm{CO}_{2}$ prices induce even greater fossil fuel substitution. The paper's results also indicate the increasing importance of the availability of advanced bioenergy technologies and biomass supply for pursuing tighter budgetsfinding only six models able to project scenarios for the smallest budget consistent with limiting warming to $1.5^{\circ} \mathrm{C}$, and none able to produce scenarios with BECCS unavailable or biomass supply constrained. Furthermore, the authors find access to advanced bioenergy technologies before 2050 more important than a doubling of bioenergy investment costs. Overall, the models feature a broad range of structural modeling approaches and parametric assumptions. Beyond the robust findings, the paper's detailed investigation of results shows considerable uncertainties regarding bioenergy use and raises questions about technology development and political choices on biomass and land-use restrictions (Bauer N, Rose SK, Fujimori S, van Vuuren DP, Weyant J, Wise $M$, Cui Y, Daioglou V, Gidden MJ, Kato E, Kitous A, Leblanc F, Sands R, Sano F, Strefler J, Tsutsui J, Bibas R, Fricko O, Hasegawa T, Klein D, Kurosawa A, Mima S, Muratori $M$. Global energy sector emission reductions and bioenergy use: overview of the bioenergy demand phase of the EMF-33 model comparison). 


\subsection{Thematic papers}

Global biomass residue feedstock supply Hanssen et al. (2019) analyze biomass residue use across models in global bioenergy deployment under the climate management scenarios, finding residues supporting up to $50 \%$ of global bioenergy demand by 2050 . Model results vary significantly, however, due to differences in model structure, assumptions, and the representation of agriculture and forestry. Nonetheless, residue supplies in 2050 are in line with literature estimates of residue availability. The authors conclude that residues are costcompetitive and can play an important role in future bioenergy use, but supply is constrained, and additional research is needed regarding uncertainties in regional forestry and agricultural production and potential residue supplies (Hanssen SV, Daioglou V, Steinmann ZJN, Frank S, Popp A, Brunelle T, Lauri P, Hasegawa T, Huijbregts MAJ, van Vuuren DP. Biomass residues as twenty-first century bioenergy feedstock - a comparison of eight integrated assessment models).

Bioenergy and food security Hasegawa et al. (2020) assess the potential implications of biomass demand for global food production, food security, and agricultural land competition. The authors find that large-scale use of bioenergy could raise food prices and increase the number of people at risk of hunger with, for instance, an increase in global bioenergy demand from 200 to $300 \mathrm{EJ}$ resulting in an additional 0 to 25 million people at risk of hunger. The authors conclude that this risk does not rule out the use of bioenergy but highlights the importance of careful implementation (Hasegawa T, Sands RD, Brunelle T, Cui Y, Frank S, Fujimori S, Popp A. Food security under high bioenergy demand toward long-term climate goals).

Bioenergy technologies Daioglou et al. (2020a) evaluate bioenergy technology modeling assumptions - elucidating and evaluating specifications and constraints. The authors evaluate the bioenergy technology representations via a series of analyses - comparing to the literature, comparing modeling details, and assessing bioenergy technology deployments projections. The authors find bioenergy technology coverage and characterization to vary substantially across models, including conversion routes, carbon dioxide capture and storage opportunities, and technology deployment constraints. However, technology specification assumptions are in line with bottom-up engineering estimates. The authors find that technology costs alone do not explain variation in bioenergy deployment projections. Other determinants found include biomass feedstock costs, carbon dioxide removal possibilities and payments, alternative mitigation options, the speed with which changes in the makeup of energy conversion facilities and integration can take place, and the relative demand for different energy services (Daioglou $V$, Rose SK, Bauer N, Kitous A, Muratori M, Sano F, Fujimori S, Gidden MJ, Kato E, Keramidas K, Klein D, Leblanc F, Tsutsui J, Wise M, van Vuuren DP. Bioenergy technologies in long-run climate change mitigation: results from the EMF-33 study).

Bioenergy with carbon dioxide capture and storage Muratori et al. (2020) increase transparency regarding the potential long-run climate management role of BECCS. The analysis begins by validating past insights and confirming large-scale cost-effective projections of notyet-commercial BECCS technologies in the future. The analysis then identifies a strong synergy between carbon dioxide capture and geologic storage (CCS) and biomass, finding bioenergy the preferred fuel for CCS as climate ambition increases; and, when BECCS is available to multiple 
sectors, finding significant BECCS deployment in liquid and hydrogen fuel production for transportation decarbonization. Furthermore, more ambitious climate goals result in more BECCS deployment in the near-term, but not over the long-run due to competition with other low-carbon technologies, land use competition effects on biomass feedstock supply, and $\mathrm{CO}_{2}$ geologic storage limitations. Without a $\mathrm{CO}_{2}$ removal technology like BECCS, the study finds limiting warming to $2{ }^{\circ} \mathrm{C}$ infeasible for some models, while those able to solve project similar levels of bioenergy use but substantially higher costs. Overall, across models, the paper finds that BECCS can contribute to $\mathrm{CO}_{2}$ emission avoidance from fossil fuel use and atmospheric carbon removal to achieve stringent climate targets, but its cumulative potential over the twenty-first century is limited by a broad range of factors (Muratori M, Bauer N, Rose SK, Wise M, Daioglou V, Cui Y, Kato E, Gidden M, Strefler J, Fujimori S, Sands RD, van Vuuren $D P$, Weyant J. EMF-33 insights on bioenergy with carbon capture and storage (BECCS)).

Global bioenergy trade Daioglou et al. (2020b) assess potential future global bioenergy trade in climate management. The authors find bioenergy trade projected to increase without climate policy and increase even further with climate policy. Also, greater climate goal ambition corresponds to an earlier increase in global bioenergy trade, but not greater trade over the longrun due to projected reductions in overall energy demand. In general, the authors find projected bioenergy trade levels with climate policy modest relative to overall consumption, but greater than present-day trade volumes of coal or natural gas, and below present-day trade volumes of crude oil. Finally, the authors find rapid growth in projected bioenergy trade volumes to not lead to energy security concerns. However, the results raise questions about infrastructure, logistics, financing, and bioenergy production and trade standards (Daioglou V, Muratori $M$, Lamers $P$, Fujimori S, Kitous A, Koberle AC, Bauer N, Junginger M, Kato E, Leblanc F, Mima $S$, Wise $M$, van Vuuren DP. Implications of climate change mitigation strategies on international bioenergy trade).

A diagnostic of regional bioenergy potential: Brazil Köberle et al. (in preparation) use Brazil as a case study to evaluate the usefulness of global integrated assessment modeling bioenergy results for policy recommendations for specific regions. Brazil is a region expected to play a large role in the potential future of global bioenergy. The analysis compares and evaluates the drivers behind variation in results for Brazil across models, exploring the role of model assumptions and structure to enhance understanding and inform national policy applications of global results. In addition to comparing models and model results, comparisons are also made to recent trends in Brazil (Köberle AC, Daioglou V, Rochedo P, Lucena AFP, Szklo A, Fujimori S, Brunelle T, Kato E, Kitous A, van Vuuren DP, Schaeffer $R$. The role of bioenergy in mitigation strategies for Brazil: a multi-model comparison exercise).

Bioenergy in global transportation Leblanc et al. (in preparation) explore the potential role of bioenergy in decarbonizing global transportation. The analysis evaluates projected biofuel growth with increasing climate ambition and for different assumptions about the availability of advanced bioenergy technologies. Among other things, the analysis investigates bioenergy's value to decarbonizing transportation with and without BECCS, as well as evaluates the opportunity for lignocellulosic-based liquid fuels (Leblanc F, Bibas R, Mima S, Muratori M, Sakamoto S, Sano F, Bauer N, Daioglou V, Fujimori S, Gidden MJ, Kato E, Tsutsui J, Wise M. The contribution of bioenergy to the decarbonization of transport: a multi-model assessment). 


\subsection{Individual modeling team papers}

End-use efficiency and bioenergy Tsutsui et al. (2020) use their global modeling framework BET-GLUE - an energy-economic module (BET) coupled to a bioenergy-land use module (GLUE) - to evaluate the role of advanced end-use technologies with scenarios that vary BECCS and end-use technology availability assumptions under a broad range of $\mathrm{CO}_{2}$ prices. Using their framework, the authors find that improving end-use efficiencies consistently decreases policy costs; however, BECCS availability does not significantly impact costs except in the most stringent scenarios. The authors conclude that advancing end-use efficiency could have a significant impact on required policy stringency and could compensate for potential constraints on bioenergy use (Tsutsui J, Yamamoto H, Sakamoto S, Sugiyama M. The role of advanced end-use technologies in long-term climate change mitigation: the interlinkage between primary bioenergy and energy end-use).

Bioenergy technology interactions Leblanc et al. (in preparation) use their global modeling framework IMACLIM-NLU - an energy-economy model Imaclim-R integrated with a land use model NLU - to explore interactions between bioenergy technologies across sectors. Among other things, the authors find that lignocellulosic fuel production delays the entry of bioelectricity with $\mathrm{CO}_{2}$ capture and sequestration. The authors also evaluate how energy demand could be impacted by agriculture, forestry, and other land use sector assumptions (Leblanc F, Brunelle T, Dumas P, Bibas R, Pelletier C, Prudhomme R. Trade-offs across energy sectors in using biomass for climate change mitigation: an integrated assessment with Imaclim-NLU).

Bioenergy and agricultural intensification Sands (in preparation), using the FARM global computable general equilibrium integrated assessment model, finds agricultural intensification implications from changes in population, dietary preferences, and climate mitigation. Among other things, BECCS is found to be a key driver of food crop yield increases, with corresponding energy crop land expansion (Sands RD. Large-scale biomass supply and agricultural intensification).

Bioenergy inter- and intra-sectoral implications Bauer et al. (2020) investigate bioenergy deployment under a broad set of alternative contexts using an iterative softlink approach between the energy model REMIND and land use model MAgPIE. The authors find that bioenergy's market share could increase significantly - to levels comparable to that of oil markets - with rapid growth in bioenergy use reaching $150 \mathrm{EJ} /$ year in 2050. However, bioenergy use varies substantially across contexts, with, for instance, bioenergy use increasing with BECCS unavailable, while biomass supply constraints lead to a reallocation of biomass toward bioenergy applications with higher $\mathrm{CO}_{2}$ capture rates. Prohibiting the use of BECCS across all sectors of the economy results in significant inter-sectoral effects and increases economic pressure on all sectors, while sector-specific bioenergy technology constraints mostly have intra-sectoral reallocation implications. Results also highlight the importance of carefully choosing variations in sensitivity analysis to effectively facilitate transparency, inform discussion, and increase policy relevance (Bauer N, Klein D, Humpenöder F, Kriegler E, Luderer G, Popp A, Strefler J. Bio-energy and $\mathrm{CO}_{2}$ emission reductions: an integrated land-use and energy sector perspective). 


\section{Conclusion}

EMF-33 undertook a novel set of multi-model scenario exercises to advance transparency and understanding of the potential contribution of bioenergy to mitigation strategies. The motivation for the study and its design are the ongoing debate on the pros and cons of bioenergy and diverging scientific outcomes in the literature. The result is an expansive set of complementary analyses and insights across this special issue that inform discussion and facilitate new research. Overall, EMF-33 highlights the unique perspective provided by long-run global integrated land use and energy system modeling that considers the full temporal and geographic scope relevant for managing the climate system, as well as the set of potential societal benefits and trade-offs across sectors, regions, and time in using bioenergy to limit climate change. The models and the papers in this special issue can help society evaluate the possibility and need for bioenergy globally, and over the very long-run, and guide exploration into finer details and implementation. Important areas for future research include land productivity, biodiversity, water quality and scarcity, income potential, bioenergy technology systems, biomass handling logistics, and climate and land policy design.

Availability of data and material Scenario results data are available upon request.

Code availability Please contact the individual modeling teams.

Authors' contributions SKR led the EMF-33 study, with NB and AP co-leads, which included development of the scenario experiments, data reporting, multi-model results assessment, and development of overview papers. SKR, NB, AP, JW, SF, PH, MW, and DvV were the study steering committee developing the overall study vision, identifying paper topics for the special issue, and providing expert guidance and feedback on every aspect of the study.

Funding This research was supported by each author's organization unless otherwise noted. SF was supported by the Environment Research and Technology Development Fund (JPMEERF20202002) of the Environmental Restoration and by the Sumitomo Foundation. The views presented here are solely those of the authors and do not represent those of their organizations or funding entities.

\section{References}

Bauer N, Rose SK, Fujimori S, van Vuuren DP, Weyant J, Wise M, Cui Y, Daioglou V, Gidden MJ, Kato E, Kitous A, Leblanc F, Sands R, Sano F, Strefler J, Tsutsui J, Bibas R, Fricko O, Hasegawa T, Klein D, Kurosawa A, Mima S, Muratori M (2018) Global energy sector emission reductions and bioenergy use: overview of the bioenergy demand phase of the EMF-33 model comparison. Climatic Change

Bauer N, Klein D, Humpenöder F, Kriegler E, Luderer G, Popp A, Strefler J (2020) Bio-energy and $\mathrm{CO}_{2}$ emission reductions: an integrated land-use and energy sector perspective. Climatic Change

Clarke L, Jiang K, Akimoto K, Babiker M, Blanford G, Fisher-Vanden K, Hourcade J-C, Krey V, Kriegler E, Löschel A, McCollum D, Paltsev S, Rose S, Shukla PR, Tavoni M, van der Zwaan BCC, van Vuuren DP (2014) Assessing Transformation Pathways. In: Edenhofer O, Pichs-Madruga R, Sokona Y, Farahani E, Kadner S, Seyboth K, Adler A, Baum I, Brunner S, Eickemeier P, Kriemann B, Savolainen J, Schlömer S, von Stechow C, Zwickel T, Minx JC (eds) Climate Change 2014: Mitigation of Climate Change. Contribution of Working Group III to the Fifth Assessment Report of the Intergovernmental Panel on Climate Change. Cambridge University Press, Cambridge

Creutzig F, Corbera E, Bolwig S, Hunsberger C (2013) Integrating place-specific livelihood and equity outcomes into global assessments of bioenergy deployment. Environ Res Lett 8:035047 
Creutzig F, Ravindranath NH, Berndes G, Bolwig S, Bright R, Cherubini F, Chum H, Corbera E, Delucchi M, Faaij A, Fargione J, Haberl H, Heath G, Lucon O, Plevin R, Popp A, Robledo-Abad C, Rose S, Smith P, Stromman A, Suh S, Masera O (2015) Bioenergy and climate change mitigation: an assessment. GCB Bioenergy 7:916-944

Daioglou V, Rose SK, Bauer N, Kitous A, Muratori M, Sano F, Fujimori S, Gidden MJ, Kato E, Keramidas K, Klein D, Leblanc F, Tsutsui J, Wise M, van Vuuren DP (2020a) Bioenergy technologies in long-run climate change mitigation: results from the EMF-33 study. Climatic Change

Daioglou V, Muratori M, Lamers P, Fujimori S, Kitous A, Koberle AC, Bauer N, Junginger M, Kato E, Leblanc F, Mima S, Wise M, van Vuuren DP (2020b) Implications of climate change mitigation strategies on international bioenergy trade, Climatic Change

Daioglou V, Woltjer G, Strengers B, Elbersen B, Barberena Ibañez G, Sánchez Gonzalez D, Gil Barno J, van Vuuren DP (2020c) Progress and barriers in understanding and preventing indirect land-use change. Biofuels Bioprod Biorefin 14(5):924-934

Gasser T, Guivarch C, Tachiiri K, Jones CD, Ciais P (2015) Negative emissions physically needed to keep global warming below $2{ }^{\circ} \mathrm{C}$. Nat Commun $6(1): 1-7$

Hanssen SV, Daioglou V, Steinmann ZJN, Frank S, Popp A, Brunelle T, Lauri P, Hasegawa T, Huijbregts MAJ, van Vuuren DP (2019) Biomass residues as twenty-first century bioenergy feedstock - a comparison of eight integrated assessment models. Climatic Change

Hasegawa T, Sands RD, Brunelle T, Cui Y, Frank S, Fujimori S, Popp A (2020) Food security under high bioenergy demand toward long-term climate goals. Climatic Change

Hof C, Voskamp A, Biber MF, Böhning-Gaese K, Engelhardt EK, Niamir A, Willis SG, Hickler T (2018) Bioenergy cropland expansion may offset positive effects of climate change mitigation for global vertebrate diversity. Proc Natl Acad Sci 115(52):13294-13299

Humpenöder F, Popp A, Bodirsky B, Weindl I, Biewald A, Lotze-Campen H, Dietrich J, Klein D, Kreidenweis U, Müller C, Rolinski S, Stevanovic M (2018) Large-scale bioenergy production: how to resolve sustainability trade-offs? Environ Res Lett 13:024011

Muratori M, Bauer N, Rose SK, Wise M, Daioglou V, Cui Y, Kato E, Gidden M, Strefler J, Fujimori S, Sands RD, van Vuuren DP, Weyant J (2020) EMF-33 insights on bioenergy with carbon capture and storage (BECCS). Climatic Change

Popp A, Rose SK, Calvin K, van Vuuren DP, Dietrich JP, Wise M, Stehfest E, Humpenöder F, Kyle P, van Vliet J, Bauer N, Lotze-Campen H, Klein D, Kriegler E (2014) Land-use transition for bioenergy and climate stabilization: model comparison of drivers, impacts and interactions with other land use based mitigation options. Clim Chang 123(3-4):495-509

Rogelj J, Popp A, Calvin KV, Luderer G, Emmerling J, Gernaat D, Fujimori S, Strefler J, Hasegawa T, Marangoni G, Krey V, Kriegler E, Riahi K, van Vuuren DP, Doelman J, Drouet L, Edmonds J, Fricko O, Harmsen M, Havlík P, Humpenöder F, Stehfest E, Tavoni M (2018) Scenarios towards limiting global mean temperature increase below $1.5^{\circ} \mathrm{C}$. Nat Clim Chang 8:325-332

Rose SK, Kriegler E, Bibas R, Calvin K, Popp A, van Vuuren D, Weyant J (2014) Bioenergy in energy transformation and climate management. Clim Chang 123(3-4):477-493

Shukla PR, Skea J, Slade R, van Diemen R, Haughey E, Malley J, Pathak M, Portugal Pereira J (eds.) (2019) Technical Summary. In: Climate Change and Land: an IPCC special report on climate change, desertification, land degradation, sustainable land management, food security, and greenhouse gas fluxes in terrestrial ecosystems [Shukla PR, Skea J, Calvo Buendia E, Masson-Delmotte V, Pörtner H-O, Roberts DC, Zhai P, Slade R, Connors S, van Diemen R, Ferrat M, Haughey E, Luz S, Neogi S, Pathak M, Petzold J, Portugal Pereira J, Vyas P, Huntley E, Kissick K, Belkacemi M, Malley J (eds)]

Smith P, Bustamante M, Ahammad H, Clark H, Dong H, Elsiddig EA, Haberl H, Harper R, House J, Jafari M, Masera O, Mbow C, Ravindranath NH, Rice CW, Robledo Abad C, Romanovskaya A, Sperling F, Tubiello F (2014) Agriculture, Forestry and Other Land Use (AFOLU). In: Edenhofer O, Pichs-Madruga R, Sokona Y, Farahani E, Kadner S, Seyboth K, Adler A, Baum I, Brunner S, Eickemeier P, Kriemann B, Savolainen J, Schlömer S, von Stechow C, Zwickel T, Minx JC (eds) Climate Change 2014: Mitigation of Climate Change. Contribution of Working Group III to the Fifth Assessment Report of the Intergovernmental Panel on Climate Change. Cambridge University Press, Cambridge

Tsutsui J, Yamamoto H, Sakamoto S, Sugiyama M (2020) The role of advanced end-use technologies in longterm climate change mitigation: the interlinkage between primary bioenergy and energy end-use. Climatic Change

Publisher's note Springer Nature remains neutral with regard to jurisdictional claims in published maps and institutional affiliations. 